\title{
Correspondence
}

\section{Tracheal compression to prevent aspiration and gastric distension}

\section{To the Editor:}

We read with very much interest the article on Pyloric Stenosis by Bissonnette and Sullivan. ${ }^{1}$ They recommended Sellick's manoeuvre during induction and intubation., ${ }^{1,2}$ However, Sellick's manoeuvre may cause obstruction of the airway in infants because identification of the cricoid ring may be difficult. As an alternative, we have applied gentle pressure over the trachea just above the sternal notch with the tip of index finger or little finger, depending upon the size of the patient, to prevent regurgitation and aspiration of gastric contents, and also gastric distension during induction anaesthesia. When expert help is not readily available, the little finger of the anaesthetist may be used as shown in the Figure.

\section{Yukio Kubota MD \\ Yoshiro Toyoda MD \\ Hiroshi Kubota MD}

Department of Anesthesia, Osaka Kohseinenkin Hospital 4-2-78, Fukushima, Fukushima-Ku, Osaka 553, Japan

\section{REFERENCES}

1 Bissonnette B, Sullivan PJ. Pyloric stenosis. Can J Anaesth 1991; 38: 668-76.

2 Dierdorf SF, Krishna G. Anesthetic management of neonatal surgical emergencies. Anesth Analg 1981: 60: 204-15.

\section{$R E P L Y$}

Thank you very much for giving me the opportunity to reply to this interesting letter from Doctors Kubota, Toyoda and Kubota.

The purpose of the Sellick manoeuvre is to ensure occlusion of the oesophagus by the cricoid cartilage. The cricoid cartilage is a complete, well-formed, rigid ring in newborn infants. ${ }^{2}$ Sealing of the oesophagus is accomplished if firm backward pressure is applied to the cricoid cartilage against the cervical vertebral bodies while the neck is in the extended position. The tracheal cartilages in infants are soft, incomplete rings, and can easily be compressed by the anaesthetist's finger. ${ }^{3}$ The softness and the absence of complete tracheal cartilage rings will not ensure that the oesophagus is entirely compressed against the cervical vertebral bodies. Furthermore, passive regurgitation could fill the upper portion of the trachea labove the compres*

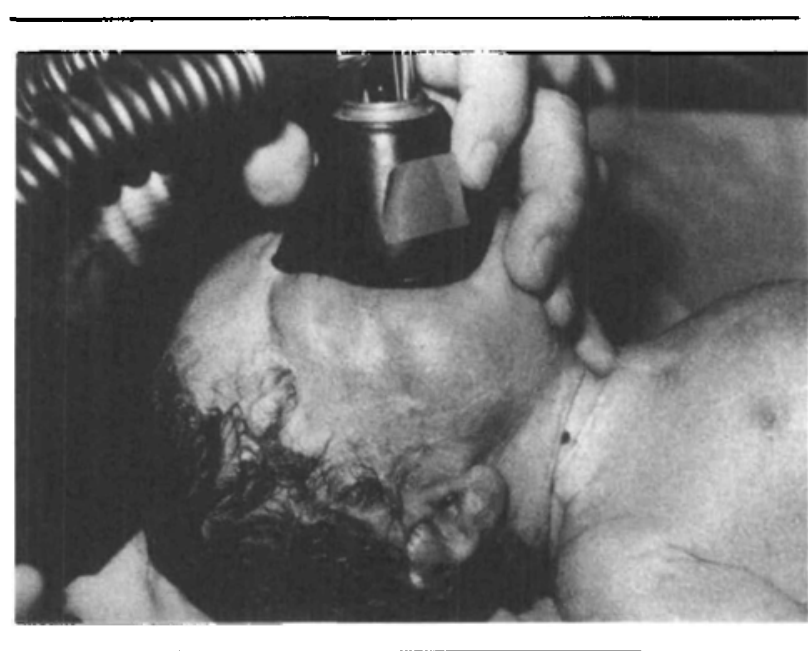

FIGURE Tracheal compression with anaesthetist's little finger while the mask is held.

sion) and cause aspiration when the finger pressure is released. The purpose of cricoid pressure is not to prevent gastric distention but rather to help prevent pulmonary aspiration during passive regurgitation. Dr. Kubota et al. suggest that in the absence of an assistant the anoesthetist's little finger could be used to ensure compression while he is holding the mask (see Figure). It is my impression that the tracheal compression will be lost during laryngoscopy and tracheal intubation since the anaesthetist would need both hands to perform this manoeuvre correctly. Cricoid pressure may be more difficult to apply in the very small infants; however, in our experience we have not encountered any difficulties or complications

Bruno Bissonnette MD

The Hospital for Sick Children

555 University Avenue

Toronto, Ontario

Canada M5G 1 X8

\section{REFERENCES}

1 Sellick BA. Cricoid pressure to control regurgitation of stomach contents during induction of anaesthesia. Lancet 1961; 2: 404-6.

2 Salem MR, Wong AY, Fizzotti GF. Efficacy of cricoid pressure in preventing aspiration of gastric contents in paediatric patients. Br J Anaesth 1972; 44: 401-4.

3 Sieward DJ. Manual of pediatric anesthesia. 2nd ed. New York: Churchill-Livingstone Inc., 1985. 